\title{
Telenovelas brasileiras, mulheres da classe dominante e a moderna tradição de gênero ${ }^{1}$
}

\section{Brazilian telenovelas, elite women and the modern tradition of gender}

\author{
Veneza Mayora Ronsini ${ }^{2}$ \\ Hellen Panitz Barbiero ${ }^{3}$ \\ Otávio Chagas Rosa \\ Marina Machiavelli ${ }^{5}$
}

Resumo: O objetivo do texto é entender os usos sociais da ficção televisiva por mulheres das frações alta e média alta da classe dominante, em particular a construção de uma feminilidade de classe, a qual é capturada pelas visões de mundo que as informantes manifestam. Tais representações se compõem de enunciados sobre as práticas cotidianas - de gestão do corpo, do trabalho e do estudo, da família e das relações amorosas - que dão sentido às práticas e as constituem. Dissertarmos sobre a incorporação das narrativas das telenovelas na formação de um capital cultural midiático que endossa o estilo de vida das mulheres heterossexuais da elite. A análise revela que a assimilação da noção hegemônica da distinção burguesa ocorre pela rejeição da figura fútil da "perua" e pela identificação com a imagem da mulher "moderna".

Palavras-chave: telenovela; usos sociais; classe dominante; feminilidade.

1 O paper é uma versão atualizada e revisada do trabalho apresentado no XXV Encontro Anual da Compós, na Universidade Federal de Goiás, em junho de 2016. O presente trabalho foi realizado com apoio da Coordenação de Aperfeiçoamento de Pessoal de Nível Superior (Capes) - Código de Financiamento 001.

2 Universidade Federal de Santa Maria (UFSM). Santa Maria, RS, Brasil. https://orcid.org/0000-0002-8669-3148. E-mail: venezar@gmail.com

3 Universidade Federal de Santa Maria (UFSM). Santa Maria, RS, Brasil. https://orcid.org/0000-0002-6716-2325. E-mail: hellenbarbiero@gmail.com

4 Universidade Federal de Santa Maria (UFSM). Santa Maria, RS, Brasil. https://orcid.org/0000-0002-9500-0008. E-mail: otaviochagasr@gmail.com

5 Universidade Federal de Santa Maria (UFSM). Santa Maria, RS, Brasil. https://orcid.org/0000-0002-2766-7636. E-mail: marinamachiavelli7@hotmail.com 
Abstract: The objective of this paper is to understand how upper middle class and upper-class women make social uses of a fictional television genre (telenovelas) in order to construct a class femininity captured by world perspectives expressed by informants. These representations are composed of statements regarding everyday practices - their own control of their physical bodies, work and study, family and love relationships - which give meaning to their practices and shape them. We address the incorporation of telenovela narratives in the formation of a media cultural capital that endorses heterosexual elite women's lifestyle. The analysis has showed that the assimilation of the hegemonic model of bourgeois distinction occurs through the identification with the image of a "modern" woman and the rejection of the "perua", shorthand for a woman with an exuberant garish but luxurious style.

Keywords: telenovela; social uses; elite; femininity. 
O objetivo do texto é entender a relação entre usos sociais da ficção televisiva por mulheres das frações média alta e alta da classe dominante e a construção de uma feminilidade de classe, capturada pelas visões de mundo que as informantes manifestam. Não se trata de instrumentalizar a categoria classe social como demarcadora das "diferenças", na crítica à maioria dos estudos realizados no Brasil (JACKS, SIFUENTES e LIBARDI, 2017): toma-se a desigualdade como pressuposto para entender a cultura a partir da posição de classe social (LAMONT, 1994). Através da recepção das telenovelas brasileiras do horário nobre da Rede Globo, produz-se um aprendizado moral pelo compartilhamento de um consenso acerca de um padrão de feminilidade de classe (RONSINI, 2015). Ao instituir esse padrão, as telenovelas administram as relações sociais entre os gêneros/classes pela norma predominante da heteronormatividade. O gênero é estruturante da textura da experiência, tal como a classe social, porque é uma forma primária de dar sentido às relações de poder baseadas nas diferenças percebidas entre os sexos (RONSINI, 2016).

No artigo, discutimos as relações entre socialidade e ritualidade (MARTÍN-BARBERO, 2009) pelo exame da experiência de 12 mulheres jovens, maduras e idosas a fim de compreender a imbricação entre texto melodramático e identidades femininas a partir de três esferas: trabalho/estudo, relações de gênero/família, aparência feminina. Com uma composição subamostral de 12 informantes, nossos resultados estão amparados em entrevistas com 24 informantes realizadas durante dois anos. Pela profundidade dos dados, acreditamos ser possível extrair indicações de validade mais geral para o estudo da condição feminina baseada em classe social em contextos urbanos de porte médio e com expressiva cultura rural. A experiência é a matéria-prima de nossa análise cultural sobre o papel da mídia na estruturação das relações sociais e das mentalidades, vale dizer, a via de acesso ao sentido produzido na socialização dos indivíduos em diferentes instituições.

A identidade feminina se origina de processos determinados pela estrutura social e pelas subjetividades: é coletiva e individual, sendo 
compartilhada por mulheres com condições de vida equivalentes. A definição do "eu" (RONSINI, 2007) depende de um "nós" cuja existência social é instituída imaginariamente pelas representações narradas e pelas ideologias. ${ }^{6} \mathrm{O}$ caráter irrefletido das identidades de gênero obstaculiza, mas não impede as transformações nas relações entre homens e mulheres heterossexuais. A avaliação sobre a trajetória pessoal - pretérita, presente e futura - é, usualmente, um balanço comparativo entre mulheres da mesma posição social ou de outra classe em uma narrativa que oculta e desvela a opressão masculina.

A representação da feminilidade é elaborada com sentimentos e definições de senso comum que são mediadas pela experiência de classe, caracterizada pela abundância de recursos econômicos e pelo acesso facilitado aos bens culturais da indústria do entretenimento e da cultura culta, os quais determinam as subjetividades (o que elas pensam que são como indivíduos), o estilo de vida e a inconsciência dos privilégios de classe.

No que concerne às relações entre as classes, a hipótese de trabalho é que o interesse das mulheres da elite pela telenovela não parece ser mera curiosidade pelo universo simbólico das classes médias e populares, ao contrário, deve-se ao contraste encenado entre as frações de classe que acaba legitimando a distinção dos bem-nascidos ou dos que ascendem pelo mérito. Sob a ótica de uma feminilidade de classe, as mulheres abastadas usufruem de uma respeitabilidade a priori tanto nas narrativas das telenovelas quanto nas relações sociais, ainda que a conquista parcial da liberdade sexual seja motivo de insegurança em função da institucionalização das desigualdades de gênero no marco da família heterossexual (ILLOUZ, 2013). A essa dupla legitimação denominamos capital cultural midiático, o qual é convertido em capital simbólico (MOORE, 2008) para as classes dirigentes como um todo na forma de prestígio pessoal e familiar. É assim que as receptoras da elite extraem

6 Tal como desenvolve Gramsci na sua teorização sobre ideologia e hegemonia, sintetizada por Terry Eagleton (1996). 
prazer do consumo das telenovelas, mesmo que estas não sirvam à distinção social nos moldes dos bens da cultura culta.

A mediação da ritualidade é capturada pelos modos de interpretar o texto ficcional e suas relações com a posição de classe. No período de coleta de dados, as informantes assistiam majoritariamente a novelas exibidas no horário nobre da Rede Globo de Televisão: Fina Estampa (Aguinaldo Silva, ago. 2011-mar. 2012), Avenida Brasil (Emmanuel Carneiro, mar. 2012-out. 2012) e Amor à Vida (Walcyr Carrasco, maio 2013-jan. 2014). O consumo de telenovela ocorre também por intermédio da rede mundial de computadores, sendo que cinco informantes, três jovens e duas maduras, acessam o site oficial da Rede Globo ou páginas com conteúdo de entretenimento para leitura dos resumos de capítulos não assistidos ou vindouros.

A epistemologia da nossa investigação segue o que designamos estudos críticos de recepção (RONSINI, 2014) e o principal método adotado são os retratos sociológicos individuais (LAHIRE, 2004), que reconstroem as trajetórias pessoais, familiares, escolares e profissionais das informantes. A genealogia da sociologia disposicional de Lahire, centrada em relatos biográficos (LAWLER, 2014), remonta ao século XIX com William Dilthey, passa pelo século XX com a escola de Chicago e se estende ao recente interesse de sociólogos pelas narrativas pessoais para inquirir sobre a produção das identidades.

\section{Classe social, gênero e telenovelas}

A premissa de que uma classe se define "no que ela tem mais essencial pelo lugar e o valor que atribui aos dois sexos e a suas disposições [...]" (BOURDIEU, 2008, p. 101-102) é o ponto de partida para a articulação entre classe, gênero e telenovela. Seguindo a lógica bourdiana, a divisão tradicional entre os gêneros no domínio da divisão sexual do trabalho e das práticas e representações tende a enfraquecer quanto maior o capital cultural herdado e o capital escolar à disposição. A ela agregamos o papel histórico das telenovelas em debater a igualdade de gênero e, pelo interesse aqui expresso, a relação afetiva heterossexual. Em tese, a mulher 
moderna burguesa pode ser definida como a que conquistou a independência econômica, a liberdade sexual e a autonomia emocional. ${ }^{7}$ Mas ela parece se restringir à independência econômica, enquanto liberdade sexual e autonomia emocional ficam a meio caminho em função da perseguição do ideal de respeitabilidade feminina associada a casamento/ união estável e maternidade tanto nas telenovelas quanto na experiência das informantes.

O consenso sobre as relações de gênero no país diz respeito, por um lado, a maior igualdade entre os gêneros nas classes médias e dominantes (MATTOS, 2006); por outro, à liberdade sexual vivida pelos setores mais esclarecidos e privilegiados, enquanto a mentalidade conservadora da maioria impede a alteração dos costumes (ALMEIDA, 2007; CARMO, 2011). A investigação de Almeida (2007) sobre a opinião dos brasileiros de todas as classes sociais e idades a respeito de "práticas sexuais liberais" aponta que os moradores de capitais são mais liberais que os de outras cidades; os que se declaram sem religião são mais liberais que os adeptos de algum credo; excetuando-se o caso da homossexualidade, os homens são mais liberais que as mulheres; a visão de mundo das pessoas com escolaridade superior é mais liberal que as de menor escolaridade.

$\mathrm{O}$ fato de as receptoras associarem as telenovelas à banalidade da distração, evitando, assim, uma aproximação com o gosto popular (LEAL, 1986) diz muito sobre a legitimidade da cultura dominante, mas pouco sobre a real importância da teleficção na construção das estruturas mentais que legitimam as hierarquias sociais e o valor da feminilidade heteronormativa dominante. $\mathrm{Na}$ interpretação das representações das telenovelas, a percepção do gênero como uma questão de aprendizado (GIDDENS, 2002) ainda contrasta com a evocação automática da natureza do masculino e do feminino.

Se, socialmente, os atributos corporais, as práticas de embelezamento e o comportamento amoroso são cruciais para a preservação da noção

7 Autonomia emocional é a capacidade de sentir, pensar e tomar decisões por conta própria (REICHERT e WAGNER, 2007). 
tradicional de respeitabilidade feminina, a encenação de estilos de vida femininos nas telenovelas tanto serve para a reprodução desse modelo quanto apresenta um retrato das mudanças operadas na condição da mulher no espaço privado e no espaço público, servindo de inspiração para atingir o ideal da mulher moderna que é protagonizado pelas tramas em grandes centros urbanos do país.

As heroínas do romance romântico moderno, tal como as das telenovelas, são, em sua maioria, independentes e corajosas. Comumente, enternecem e modificam a masculinidade supostamente intratável de seus amados, produzindo ativamente o amor (GIDDENS, 1993). Esse caráter potencialmente "subversivo" do amor romântico, contudo, se manteve latente pela imprescindível associação com o casamento - e com a maternidade; e também pela ideia de que, uma vez encontrado o amor verdadeiro, ele seria "para sempre".

Como veremos na análise das representações da feminilidade, as receptoras, residentes em cidades do interior do Rio Grande do Sul, mostraram dificuldades em: aceitar a liberdade sexual feminina; se desvincular da ideia de amor romântico, vale dizer, das suas associações com a passividade feminina na conquista amorosa e com o feminino e o masculino como antíteses, porque as origens da moderna tradição do amor romântico se podem vislumbrar na empatia com as funções cuidadoras da mãe e esposa e nos conflitos típicos do amor confluente (GIDDENS, 1993), onde a paixão amorosa é exercitada por homens e mulheres.

\section{Perfis sociológicos individuais}

Além da classificação de acordo com a posição de classe ${ }^{8}$ e da orientação sexual heteronormativa, as informantes foram distribuídas por geração. $\mathrm{O}$ arco geracional das entrevistadas ${ }^{9}$ jovens se estende dos 20

8 A categorização da amostra em frações de classe considerou o capital econômico (membro mais bem situado da família), o capital cultural (escolaridade, consumo de bens materiais e culturais) e o capital simbólico (autoridade e prestígio).

9 Os nomes das informantes são fictícios. Os dados das cinco entrevistas aplicadas com cada uma delas foram categorizados com o auxílio do software NVIVO9. 
aos 24 anos; das maduras, de 30 a 50; das idosas, de 68 a 76. Os retratos sociológicos - que oferecem um panorama da mediação da experiência - abrangem os dados demográficos das informantes (idade, ocupação profissional, estado civil, local de residência), o capital cultural escolar, o capital cultural objetivado no consumo de bens da cultura culta e massiva, assim como os desejos expressos sobre quem gostariam de ser e o que gostariam de aprender. Estes revelam quais capitais legitimam o estilo de vida da mulher burguesa.

Cinco entrevistadas, as idosas Lia, Liliane e Soraia e as maduras Roberta e Rute, são as mais bem situadas economicamente em suas famílias. Outras cinco, a madura Marina e todas as jovens, Ísis, Gina, Lena e Taís, são sustentadas pelos pais. O pai de Marina é tenente do Exército aposentado; o de Ísis é engenheiro civil; o de Gina, proprietário de uma gráfica; a mãe de Lena é professora de universidade federal e a de Taís, proprietária de terras e de uma empresa de seguros. Nas famílias da idosa Cora e da madura Neusa, os maridos são os membros mais bem situados - respectivamente, coronel veterinário aposentado e médico anestesista e sócio de clínica privada. Lia, Liliane, Roberta, Neusa, Ísis e Gina foram classificadas na fração alta da classe dominante, enquanto as outras seis - Soraia, Cora, Marina, Rute, Lena e Taís - foram classificadas na fração média alta.

As jovens Gina, Taís e Lena são naturais de Santa Maria e Ísis, de uma pequena cidade da região noroeste do Rio Grande do Sul. Ísis (24) e Gina (23), classe alta, cursam, respectivamente, Direito e Arquitetura em universidades federais. Além de estudar, Ísis é estagiária do Ministério Público Federal. Lena (20) e Taís (24) pertencem à classe média alta, a primeira cursa Jornalismo e a segunda é formada em Publicidade e Propaganda em instituição privada de ensino superior, trabalha na área de comunicação e marketing de uma corretora de seguros (pertencente à sua mãe) e em uma escola profissionalizante que oferece cursos de MBA e pós-graduação. Duas das entrevistadas (Taís e Lena) são filhas de pais divorciados e residem com a mãe. Gina reside com o pai e sua mãe é falecida. Isís reside em Santa Maria com a irmã, estudante 
de Engenharia Civil, e os pais moram no interior do estado. Todas são solteiras.

As maduras nasceram e residem em Santa Maria. Roberta e Neusa pertencem à classe alta e completaram o ensino superior na área de trabalho atual. Neusa é assistente social em hospital e concluiu o doutorado em Serviço Social em universidade privada. Roberta é farmacêutica, concluiu o mestrado em Ciências Farmacêuticas em universidade federal e trabalha em laboratório de análises clínicas do qual é sócia. Marina e Rute pertencem à classe média alta, a primeira se formou em Ciências Contábeis e fez especialização em Recursos Humanos, a segunda é graduada em Artes Plásticas. Marina trabalhou como contadora em um escritório, mas atualmente tem se dedicado aos estudos para concursos. Rute é sócia-proprietária de uma empresa de decoração e eventos. Roberta e Marina são solteiras: a primeira mora sozinha e a segunda, com os pais. Rute é divorciada e mora com os dois filhos adolescentes. Neusa é casada e mora com o marido e os dois filhos.

As idosas, com exceção de Lia, que reside em pequena cidade da região do Alto Jacuí, RS, são naturais de Santa Maria. Lia e Liliane pertencem à classe alta e Soraia e Cora, à média alta. Liliane e Soraia são aposentadas, respectivamente, como professora universitária e professora estadual de Português. Liliane se graduou em Filosofia e concluiu o mestrado em Educação, sendo que sua maior fonte de renda provém das suas propriedades rurais. Soraia completou o magistério e não concluiu o ensino superior, mas vive também com a pensão do falecido marido, que trabalhava como gerente de banco. Lia e Cora são donas de casa. A primeira, por determinação do pai, não chegou a completar o fundamental e a segunda concluiu o ensino médio. A renda de Lia se origina da empresa, administrada pelos irmãos, que comercializa grãos e insumos agrícolas. Seu marido era agricultor e pecuarista. Todas as informantes são mães. Lia e Soraia são viúvas e ambas têm quatro filhos; Cora é casada com um veterinário militar aposentado e tem três filhos; Liliane é divorciada e tem um filho. Lia e Liliane moram sozinhas; 
Cora, com o marido; Soraia, com uma das filhas. Apenas Liliane tem ensino superior completo.

$O$ alto capital escolar das informantes - cinco têm ensino superior incompleto (quatro jovens e uma idosa) e quatro (uma idosa e três maduras) são doutoras, mestres ou especialistas - reflete o nível de instrução das mulheres ocupadas com superior completo ou incompleto na cidade de Santa Maria, que é superior ao da média nacional (IBGE, 2011, 2015). Entretanto, o capital objetivado na forma de diplomas não garante a disposição para a cultura legítima, uma vez que ela depende também, entre outros fatores, do capital cultural herdado da família (BOURDIEU, 2008). É assim que a maior familiaridade com os bens da cultura culta coincide com a mais elevada titulação entre as idosas (Liliane), mas, entre as maduras, é Marina quem possui maior capital cultural objetivado, apesar da titulação de especialista em comparação com os títulos de doutor e mestre de Neusa e Roberta. Entre as jovens, todas com escolaridade equivalente, o consumo mais regular é o de cinema massivo e shows, com exceção de Gina, que mensalmente aprecia exposições de arte, anualmente frequenta o teatro e/ou espetáculos de dança. Ísis e Lena também apreciam ocasionalmente peças teatrais, enquanto Taís usufrui do cinema e de shows.

As figuras femininas ideais contemplam personalidades públicas e midiáticas de prestígio social e profissional. A idosa Liliane e as jovens Taís e Lena direcionam suas predileções às mulheres elegantes, cujas carreiras giram em torno da moda/alta-costura, respectivamente citadas: a estilista Coco Chanel; a consultora de moda Constanza Pascolato; e a editora da Elle Brasil, Susana Barbosa. Kate Middleton é a indicação da jovem Gina em função de sua beleza e “poder”. Evita Perón é o modelo de mulher almejado pela madura Neusa. A apresentadora Hebe Camargo e a atriz Fernanda Montenegro são as escolhas, respectivamente, da madura Roberta e da idosa Lia. A admiração pelo violinista e regente Andre Rieu faz a idosa Soraia sonhar com uma carreira musical em orquestra. A madura Marina encontra na "inteligência" e na "sensibilidade" da escritora Martha Medeiros os atributos que considera 
desenvolver. A idosa Cora e a jovem Ísis, em contrapartida, não indicaram nenhum nome em particular. A primeira relata a frustração de não ter sido "uma mulher de negócios" e a segunda projeta seu futuro como uma mulher "muito bonita, muito rica, muito inteligente e bem-sucedida em nível profissional, pessoal e amoroso”. A madura Rute, por fim, legitima suas qualidades como "mãe" e "dona de casa".

Os desejos manifestos sobre aquilo que "gostariam de aprender se tivessem a chance" se apresentam como atividades complementares ao capital cultural já detido. São eles: aprender ou aperfeiçoar idiomas (Liliane, Roberta, Rute, Neusa, Taís, Gina, Marina), estudar canto e/ ou instrumentos musicais (Cora, Gina, Lena, Ísis), graduar-se em curso superior (Cora) e aprender a utilizar a internet (Lia). Os capitais mais mobilizados para a legitimação da autoidentidade são o econômico, o cultural (intelectual e escolar) e o simbólico (gênero): riqueza, sucesso profissional, domínio ou fluência de uma língua estrangeira, inteligência, elegância, beleza.

\section{Definindo o que é ser mulher}

Quando solicitadas a se autodefinirem, nenhuma das entrevistadas foi induzida a falar sobre o pertencimento de classe. Mesmo assim, a maioria - todas as jovens, as maduras Rute e Marina e as idosas Liliane, Soraia e Cora - caracterizam a si mesmas pelo capital econômico ou cultural ("boa educação", "postura", capacidade de liderança, apreço por viagens, elogio ao cultivo da literatura, do teatro, da música clássica etc.). Além disso, sete informantes se autodefinem por um capital simbólico baseado em um habitus de gênero: as idosas Soraia e Cora por serem mães e esposas dedicadas; a idosa Lia pela disposição à organização; a madura Marina por se considerar uma "mulher moderna"; a madura Roberta pelo comprometimento com a união familiar; e as jovens Taís e Lena exaltam, respectivamente, as virtudes da delicadeza e da vaidade/afetividade.

Nas representações das relações de gênero, descritas a seguir, fica clara a contradição entre dominação e submissão. Ao pensarem sobre 
os aspectos positivos da feminilidade, reproduzem a visão hegemônica baseada na maternidade, na natureza sensível e emocional da mulher e no prazer com as práticas do embelezamento. Apenas duas informantes, a idosa Liliane e a jovem Gina, reivindicam “autonomia” plena para as mulheres (incluindo a liberdade sexual), enquanto a madura Marina acredita que a mulher já tem os mesmos direitos e autonomia em relação ao homem. A madura Neusa relembra sua inveja juvenil da liberdade dos rapazes.

Quando avaliam "as piores coisas de ser mulher", as desvantagens se dividem entre as atribuídas às desigualdades de gênero e aquelas entendidas como oriundas da natureza biológica (corporal e emocional/ sensível), estas enfatizadas pela idosa Cora e pelas jovens Lena, Ísis e Roberta. As desigualdades de gênero - relacionadas à sobrecarga das demandas no espaço público e privado, ao autoritarismo do cônjuge ou à ausência de credibilidade no mercado de trabalho - são destacadas por oito informantes: as quatro idosas (Lia, Soraia, Cora, Liliane), as maduras Neusa e Marina e as jovens Lena e Gina. Observa-se, portanto, que a representação da feminilidade como natureza rivaliza com os determinantes sociais e culturais da opressão feminina, obstaculizando sua percepção.

Para 11 informantes, com exceção da jovem Taís, a vida da mulher é mais difícil que a do homem em função de suas múltiplas jornadas. Reprovam a comodidade dos homens, quase exclusivamente dedicados ao trabalho fora do lar, sem reivindicar a divisão de tarefas, facilitadas pelo auxílio de diaristas ou empregadas domésticas. A única que defende a competência natural da mulher para os assuntos domésticos é Marina. Liliane e Lena destacam, respectivamente: a exigência da beleza como critério para a valorização social da mulher e a desigualdade salarial; a restrição da liberdade feminina no casamento e a aceitação social da infidelidade masculina. Quanto às dificuldades com a educação dos filhos, há consenso sobre o compartilhamento da responsabilidade entre pai e mãe. Outro desafio que torna a vida das mulheres mais difícil que a dos homens é a necessidade do cuidado com a aparência, 
apontada por seis informantes de diferentes gerações. Observa-se, assim, que apenas duas informantes são capazes de questionar aspectos-chave da subordinação feminina - a desigualdade econômica no mercado de trabalho e a restrição da liberdade feminina pelo casamento.

$\mathrm{Na}$ escolha da mãe ou figura feminina que exerceu/exerce o papel de mulher exemplar, o motivo predominante da admiração se deve à conquista da independência econômica, paralelamente ao zelo pelo núcleo familiar. O corte geracional é nítido, uma vez que apenas as idosas (Lia, Soraia, Cora) exaltam as virtudes da feminilidade tradicional da mulher que procria e cuida do lar.

O entendimento das entrevistadas acerca do que consideram uma mulher sensual é permeado pelo recato feminino: reprovação quanto à exibição dos atributos corporais e ocultação dos impulsos sexuais. Se o cuidado com a aparência denota as intenções e, por isso, não deve se exagerado, os modos - de caminhar, sentar, comer, falar, olhar e sorrir - são valorizados pelas informantes como propriedades da mulher bem-comportada. A vulgaridade é o avesso da sensualidade e se define pelas roupas curtas e justas e pelos modos de se portar socialmente. Outra característica das mulheres vulgares é manter relação sexual com vários parceiros sucessiva ou simultaneamente. A idosa Cora cita espontaneamente a figura televisiva da Mulher Melancia, enquanto a jovem Lena usa o termo "periguete" para designar a mulher vulgar.

Para as 12 entrevistadas, o cuidado com a aparência é próprio da definição de feminilidade. O conceito de beleza está associado ao cuidado do corpo, da aparência e a frase emblemática é "Não existe mulher feia, existe mulher pobre” (Gina, 23 anos). A obrigatoriedade das práticas de embelezamento é questionada, mas todas se adéquam ao padrão através dos cuidados com a aparência (pele, cabelo, unhas) e forma corporal pela prática de atividades físicas e intervenções cirúrgicas. A reprodução da desigualdade de gênero ou os avanços para a sua superação - sobretudo vinculados ao estímulo familiar à independência econômica - têm origem nos ensinamentos que receberam de suas famílias primordiais. $\mathrm{Na}$ fala de nove mulheres, a maioria maduras e jovens, constata-se a 
existência de uma educação que contribui para a emancipação feminina baseada na autonomia econômica. A transformação geracional é nítida no tocante à educação sexual preventiva para evitar doenças e gravidez indesejada: enquanto as jovens receberam essas informações, as idosas e maduras necessitavam de constantes permissões para o convívio com rapazes na juventude.

As representações sobre a condição feminina se apresentam fragmentadas. Por um lado, a insatisfação mais recorrente é com a sobrecarga de tarefas femininas no gerenciamento do espaço doméstico e da sua compatibilização com o trabalho fora do lar. Minoritariamente, apontam-se as dificuldades para as mulheres serem respeitadas no mercado de trabalho e compara-se a liberdade sexual do homem com a falta de liberdade sexual da mulher.

Em contraposição às mulheres das classes populares, a condição feminina não é vista como um destino com o qual precisam se resignar (RONSINI et al., 2015): a maternidade, o embelezamento, o cuidado com o outro, a respeitabilidade moral no exercício da sexualidade são "escolhas" que elevam a mulher a um estatuto especial. O ideal feminino é a mulher capaz de dar conta de todos os aspectos da vida privada e pública, além de ser reconhecida profissionalmente e legitimada pela aparência.

\section{A mulher nas telenovelas}

As receptoras foram questionadas sobre o papel da telenovela na compreensão da condição feminina e se há identificação entre elas e personagens. A maioria pensa que as narrativas contribuem para refletir sobre a condição feminina, mas seis delas negam a identificação com personagens (a idosa Cora, a madura Rute e as jovens Ísis e Gina) ou com personagens de classe alta (as idosas Lia, Liliane e Cora e as jovens Ísis e Gina), alegando distanciamento de condutas maternas reprováveis, demonstrações de futilidade ou características mais aproximadas à classe trabalhadora. 
Outras cinco - a idosa Soraia, as maduras Roberta, Neusa e Rute e a jovem Lena - se identificam, na devida ordem, com o equilíbrio emocional da personagem Débora (Avenida Brasil); seu romantismo e desejo de constituir família; a vaidade e bom gosto/elegância de Tereza Cristina (Fina Estampa); personagens que ascenderam como Griselda (Fina Estampa); a condição de classe "e a personalidade romântica de Débora”. Duas entrevistadas, a madura Marina e a jovem Taís, optaram por destacar personagens de classe popular: Nina (Avenida Brasil), por sua determinação e desejo de justiça, e Amália (Fina Estampa), pela delicadeza e elegância. A identificação ocorre com personagens que representam o modo de vida das classes altas e médias e que usufruem da independência econômica ou com a mulher de classe média ou trabalhadora que atende às esferas pública e privada. Quando isso ocorre, enfatizam a proximidade no tocante a gênero e exaltam as diferenças de classe entre elas e as personagens.

A distinção nos modos de ser entre as classes é reforçada quando são interpeladas a descrever a trajetória de personagens de classes altas e populares. Prevalecem, entre as personagens femininas associadas às classes altas, aquelas cuja posição de classe advém de heranças familiares ou da ascensão proveniente do casamento. Dez informantes referenciaram negativamente mulheres que não tinham ocupação profissional.

Também é consenso a avaliação quanto à elegância das mulheres ficcionais de classe alta, descritas como "bem-vestidas" e "bemarrumadas". Apesar de julgarem desviante o caráter de boa parte delas - Tereza Cristina (Fina Estampa), "mulheres do Cadinho" (Avenida Brasil) e Carminha (Avenida Brasil) -, o modo como se vestem ou se apresentam socialmente é legitimado como uma referência da mulher "chique" e "charmosa". Quanto à escolaridade das personagens mencionadas, metade de nossas entrevistadas as descrevem como tendo elevada formação escolar. A outra metade relatou não recordar essa informação ou que não havia sido apresentado explicitamente na telenovela. 
A falta de vínculos afetivos das personagens de classe alta com a família é outro ponto reincidente. Para oito delas, as personagens elencadas não cumpriam o papel que presumem adequado para a mulher no âmbito doméstico: "Não é boa mãe", "Individualista" e "Pensa mais nela do que na família”.

Solicitadas a reportar trajetórias de personagens femininas de classe popular, observamos a predominância de um modelo quase oposto ao da representação da classe alta, sintetizado nos adjetivos "batalhadora" e "lutadora". Com exceção da idosa Soraia e da jovem Lena, as demais acentuam a presença de mulheres honestas e trabalhadoras que promovem de maneira digna o sustento próprio e dos filhos. A percepção de nossas entrevistadas quanto ao capital cultural escolar das referidas mulheres é unânime: tais personagens tinham baixa ou nenhuma escolaridade, reconhecida pelos modos de falar ou pelas atividades profissionais "braçais".

A compreensão quanto à aparência da personagem feminina de classe popular é unanimemente caracterizada pelo desleixo, pela vulgaridade e pelo mau gosto: "Seios de fora, bunda grande, cabelos soltos, vestido curto, belas pernas. Ela não é um tipo refinado" (Liliane, 72 anos, sobre Dagmar em Fina Estampa); "Uma periguete total, de topzinho, cintinho brilhante na barriga, legging bem justa e um saltão. Anda rebolando e tem cabelão comprido" (Lena, 20 anos, sobre Suelen em Avenida Brasil); "Ela é exótica! Ela usa uma flor enorme no cabelo, as roupas são ridículas!” (Soraia sobre Márcia em Amor à Vida).

As informantes idosas têm uma noção positiva das personagens que encarnam os valores conservadores, associando-as à indissolubilidade do casamento, aos ideais de respeitabilidade feminina (pureza) e à religiosidade, com exceção de Liliane - por sua trajetória familiar, renda elevada combinada a uma vivência cosmopolita em viagens e cursos no exterior, convívio com intelectuais e artistas durante a formação acadêmica. Observa-se a clivagem geracional na medida em que maduras e jovens entendem que personagens conservadoras são "antiquadas". 
Sem distinção de geração, a avaliação das características da personagem liberal como sinônimo de mulher moderna é aquela que trabalha e/ou tem autonomia emocional. Outros aspectos que caracterizam o pensamento e as ações de personagens modernas é, para a maioria, a desaprovação da infidelidade masculina. As mais conservadoras criticam tais condutas, mas as justificam pela crença no instinto do homem.

A iniciativa na conquista amorosa é tema pouco debatido. A admissão da experiência sexual como questão de desejo para ambos os sexos é mais comum entre maduras e jovens, mas são as jovens que demonstram inconformidade com certa valorização da castidade feminina em contraposição à liberdade masculina. Os traços da visão patriarcal aparecem na defesa do pudor da personagem feminina que é desejada pelos homens, na reprovação da personagem que deseja um relacionamento "aberto", na vulgaridade de Suelen, na reprovação veemente da infidelidade feminina quando contraposta à infidelidade masculina.

Todas as gerações elogiam a independência econômica manifestada pela personagem moderna, preservando o imaginário conservador do amor romântico em contrapartida ao amor confluente: contrastam a liberdade sexual ao recato feminino, uma essência feminina e outra masculina, sobretudo quanto à ética do cuidado e a busca pelo prazer sexual. Aprovam a personagem que encarna a mulher moderna, com ênfase na dedicação ao trabalho e à família, e rejeitam a "perua" por sua futilidade. A observância da submissão de gênero nas tramas, que é reprovada, limita-se à aceitação da infidelidade marital ou à extrema subserviência feminina ao marido. As condutas sexuais das personagens vilãs de classe alta são questionadas e tidas como comportamentos individuais desviantes que não estão associados ao padrão esperado para as elites. Por contraste, as práticas sexuais das personagens de classe popular, consideradas inapropriadas, são vistas como atributos de mulheres de origem humilde, assim como o desleixo na aparência das honestas e trabalhadoras. 
Seja mencionando personagens da dramaturgia ou se referindo a problemas familiares e pessoais, o tema dos direitos das minorias sexuais permanece silenciado ou se polariza entre "desaprovação" e comentários sobre discriminação dos "gays e lésbicas". O feminismo, ao contrário, é veementemente rejeitado como "radical" para a maioria.

\section{Conclusões}

As telenovelas oferecem às mulheres das classes dominantes a confirmação de um padrão aceite de comportamento sexual que envolve a comedida experimentação sexual para escolher o marido ou namorado ideal; o endosso do estilo de vida burguês baseado na elegância; o elogio à mulher "moderna" dedicada à carreira e à família que se aproxima do modelo da "batalhadora" de classe popular. É nesse aspecto que ocorre uma identificação com as personagens de classe popular baseada na experiência de gênero.

O princípio sexista da vida privada como responsabilidade feminina é vivido pela totalidade das informantes, mesmo pelas que trabalham fora do lar, que ainda são encarregadas do peso das tarefas ou da sua administração com o auxílio substantivo das empregadas domésticas. A consciência dessa forma de desigualdade é apaziguada pela adoção da noção de uma natureza feminina - cuidadora/protetora, amorosa, ágil para resolver tudo ao mesmo tempo - vista como um dom, uma habilidade especial. Por isso, os mecanismos de identificação com a heroína moderna da dramaturgia televisiva operam no reforço do sexismo.

O exame da recepção das telenovelas permite revelar a luta de classes no campo dos valores morais. A contraposição entre vilãs endinheiradas e heroínas trabalhadoras é amenizada pelo recurso do distanciamento em relação à futilidade de classe/gênero e à identificação com mulheres "modernas", sejam elas trabalhadoras que ascenderam socialmente e se dedicam ao trabalho e à família ou as bem-nascidas que encarnam o ideal da mulher que conquistou um lugar no mercado de trabalho sem abrir mão da família e do amor romântico. A "mulher de classe" 
das telenovelas é o espelho da respeitabilidade burguesa, visto que a ausência das virtudes morais das vilãs são patologias individuais que não ameaçam o modelo dominante da feminilidade.

A feminilidade de classe significa manter os valores tradicionais das relações de gênero preconizados pelo romantismo - heterossexualidade, proteção, idealização da pessoa amada, passividade feminina - e viver as benesses do romantismo moderno baseado no prazer sexual. A sombra da tradição permanece efetiva e de forma bem visível no controle das condutas sexuais e na preocupação com a respeitabilidade, talvez porque metade da amostra seja composta por mulheres solteiras e em idade de concorrer no mercado matrimonial em um centro urbano de porte médio.

Se as mulheres das classes populares endossam o estilo de vida burguês e sentem vergonha por não realizá-lo, a violência simbólica à qual as mulheres da classe dominante estão submetidas consiste em gerenciálo e, assim, garantir a sua reprodução, em que pesem as dificuldades que encontram para equilibrar o coquetismo com a independência econômica e o cuidado da esfera doméstica. ${ }^{10}$

\section{Referências}

ALMEIDA, A. C. A cabeça do brasileiro. Rio de Janeiro: Record, 2007.

AMOR À VIDA. Roteiro: Walcyr Carrasco. Direção-geral: Mauro Mendonça Filho. Rio de Janeiro: Rede Globo de Televisão, 2013-2014.

AVENIDA BRASIL. Roteiro: João Emanuel Carneiro. Direção-geral: Amora Mautner e José Luiz Villamarim. Rio de Janeiro: Rede Globo de Televisão, 2012.

BOURDIEU, P. A distinção: crítica social do julgamento. São Paulo: Edusp; Porto Alegre: Zouk, 2008.

10 As contribuições de cada autor para o desenvolvimento do artigo estão descritas a seguir: esta investigação contempla parcialmente os resultados da pesquisa "Aprendendo a ser mulher 'de classe’ com a mídia” (UFSM/CNPq), coordenada pela professora doutora Veneza Mayora Ronsini. Para a produção deste artigo, os autores estiveram conjuntamente envolvidos na coleta, na descrição dos dados e na redação final. 
CARMO, P. S. do. Entre a luxúria e o pudor: a história do sexo no Brasil. São Paulo: Octavo, 2011.

EAGLETON, T. A ideologia e suas vicissitudes no marxismo ocidental. In: $\square \mathbf{I}$ EK, S. (Org.). Um mapa da ideologia. Rio de Janeiro: Contraponto, 1996. p. 179-226.

FINA ESTAMPA. Roteiro: Aguinaldo Silva, Maria Elisa Berredo, Nelson Nadotti e Patrícia Moretzsohn. Direção-geral: Wolf Maya. Rio de Janeiro: Rede Globo de Televisão, 2011-2012.

GIDDENS, A. A transformação da intimidade: sexualidade, amor e erotismo nas sociedades modernas. São Paulo: Unesp, 1993.

. Modernidade e identidade. Rio de Janeiro: Zahar, 2002.

ILLOUZ, E. Por qué duele el amor. Buenos Aires: Katz, 2013.

INSTITUTO BRASILEIRO DE GEOGRAFIA E ESTATÍSTICA (IBGE). Censo Demográfico 2010: resultados do universo. Rio de Janeiro: IBGE, 2011. Disponível em: http://www. censo2010.ibge.gov.br. Acesso em: 20 jan. 2016.

. Pesquisa Nacional de Análise por Domicílios 2014. Rio de Janeiro: IBGE, 2015. Disponível em: http://www.ibge.gov.br. Acesso em: 20 jan. 2016.

JACKS, N.; SIFUENTES, L.; LIBARDI, G. Classe social: elemento estrutural (des) considerado nas pesquisas de recepção e consumo midiático. In: JACKS, N. (Coord.); PIEDRAS, E.; PIENIZ, M.; JOHN, V. (Orgs.). Meios e audiências III: reconfigurações dos estudos de recepção e consumo midiático no Brasil. Porto Alegre: Sulina, 2017.

LAHIRE, B. Retratos sociológicos: disposições e variações individuais. Porto Alegre: Artmed, 2004.

LAMONT, M. Money, morals, E manners. Chicago: Chicago Press, 1994.

LAWLER, S. Identity. Sociological perspectives. Cambridge, Reino Unido: Polity Press, 2014.

LEAL, O. A leitura social da novela das oito. Petrópolis: Vozes, 1986.

MARTÍN-BARBERO, J. Uma aventura epistemológica. Matrizes, São Paulo, v. 2, n. 2, p. 143-162, jun. 2009.

MATTOS, P. A mulher moderna numa sociedade desigual. In: SOUZA, J. (Org.). A invisibilidade da desigualdade brasileira. Belo Horizonte: UFMG, 2006.

MOORE, R. Capital. In: GRENFELL, M. (Ed.). Pierre Bourdieu: key concepts. Stocksfield: Acumen, 2008. p. 101-118.

REICHERT, C. B.; WAGNER, A. Considerações sobre a autonomia na contemporaneidade. Estudos e Pesquisas em psicologia, Rio de Janeiro, v. 7, n. 3, p. 1-14, dez. 2007. Disponível em: http://pepsic.bvsalud.org/pdf/epp/v7n3/v7n3a04.pdf. Acesso em: 30 jan. 2016.

RONSINI, V. Carne e alma: ensaio sobre feminilidade, capital simbólico e melodrama. In: CAMPANELLA, B.; BARROS, C. (Orgs.). Etnografia \& consumo midiático: novas tendências e desafios metodológicos. Rio de Janeiro: E-papers, 2016. p. 133-156.

RONSINI, V. El polvo de la tradición en la carretera de los Estudios Culturales. In: MALDONADO, A. E. (Coord.). Panorâmica da investigação em comunicação no Brasil. Salamanca: Comunicación Social, 2014. p. 75-98. 
RONSINI, V. Mercadores de sentido: consumo de mídia e identidades juvenis. Porto Alegre: Sulina, 2007.

. Telenovelas e a questão da feminilidade de classe. In: ENCONTRO ANUAL DA COMPÓS, XXIV, 2015, Brasília. Anais... Brasília: UCB, 2015. p. 1-19.

RONSINI, V.; BARBIERO, H.; CHAGAS, O.; MACHIAVELLI, M. Os sentidos das telenovelas nas trajetórias sociais de mulheres das classes populares. In: CONGRESSO BRASILEIRO DE CIÊNCIAS DA COMUNICAÇÃO, XXXVIII, 2015, Rio de Janeiro. Anais... Rio de Janeiro: UFRJ, 2015. p. 1-23.

\section{Sobre os autores}

Veneza Mayora Ronsini - Professora titular do Departamento de Ciências da Comunicação da Universidade Federal de Santa Maria (UFSM) e professora do Programa de Pós-graduação em Comunicação (PPGCOM). Pesquisadora PQ2 do CNPq. Estágio sênior na Nottingham Trent University (Inglaterra) com bolsa Capes. Doutora em Sociologia pela Universidade de São Paulo com bolsa-sanduíche (Capes) na University of California (EUA).

Hellen Panitz Barbiero - Mestre em Comunicação Midiática pelo PPGCOM/ UFSM com bolsa Capes.

Otávio Chagas Rosa - Mestre em Comunicação Midiática pelo PPGCOM/ UFSM com bolsa Capes.

Marina Machiavelli - Mestre em Comunicação Midiática pelo PPGCOM/ UFSM com bolsa Capes.

Data de submissão: 27/09/2018

Data de aceite: 03/06/2019 